\title{
Serine 124 completes the Tyr, Lys and Ser triad responsible for the catalysis of human type 1 3ß-hydroxysteroid dehydrogenase
}

\author{
J L Thomas, W L Duax ${ }^{1,2}$, A Addlagatta ${ }^{2,3}$, L A Scaccia, K A Frizzell and \\ S B Carloni
}

Division of Basic Medical Sciences and Department of Obstetrics-Gynecology, Mercer University School of Medicine, Macon, Georgia, USA

${ }^{1}$ Hauptman-Woodward Medical Research Institute, Buffalo, New York, USA

2State University of New York, Buffalo, New York, USA

${ }^{3}$ Institute of Molecular Biology, Howard Hughes Medical Institute and Department of Physics, University of Oregon, Eugene, Oregon, USA

(Requests for offprints should be addressed to James L Thomas, Division of Basic Medical Sciences, 1550 College Street, Mercer University School of Medicine, Macon, Georgia 31207, USA; Email: Thomas_J@mercer.edu)

\begin{abstract}

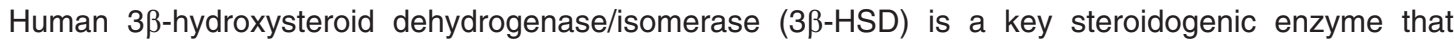
catalyzes the first step in the conversion of circulating dehydroepiandrosterone (DHEA), pregnenolone or $17 \alpha$-hydroxypregenolone to produce the appropriate, active steroid hormone(s): estradiol, testosterone, progesterone, aldosterone or cortisol respectively. Our mutagenesis studies have identified Tyr154 and Lys 158 as catalytic residues for the $3 \beta$-HSD reaction. Our three-dimensional homology model of $3 \beta-\mathrm{HSD}$ shows that Tyr154 and Lys158 are oriented near the 3 $\beta$-hydroxyl group of the bound substrate steroid, and predicts that Ser123 or Ser124 completes a Tyr-Lys-Ser catalytic triad that operates in many other dehydrogenases. The S123A and S124A mutants of human type $13 \beta$-hydroxysteroid dehydrogenase/

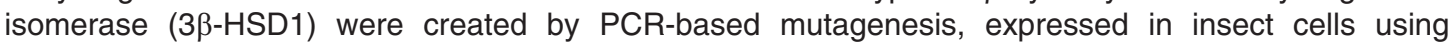
baculovirus and purified to homogeneity. The S124A mutant exhibits no $3 \beta$-HSD activity and has a $K_{m}$ value $(83.6 \mu \mathrm{M})$ for the isomerase substrate that is threefold greater than that of wild-type 1 isomerase. In contrast, S123A has substantial $3 \beta$-HSD activity (DHEA $K_{\mathrm{m}}=11.2 \mu \mathrm{M} ; \mathrm{k}_{\text {cat }}=0.8 \mathrm{~min}^{-1}$ ) and utilizes isomerase substrate, 5-androstene-3,17-dione, with a $K_{\mathrm{m}}$ value $(27.6 \mu \mathrm{M})$ that is almost identical to wild-type. The $K_{\mathrm{m}}$ value $(4.3 \mu \mathrm{M})$ of S124A for NADH as an allosteric activator of isomerase is similar to that of the wild-type 1 enzyme, indicating that Ser124 is not involved in cofactor binding. S123A utilizes $\mathrm{NAD}$ as a cofactor for $3 \beta-\mathrm{HSD}$ and $\mathrm{NADH}$ as the activator for isomerase with $K_{\mathrm{m}}$ values that are similar to wild-type. The $3 \beta$-HSD activities of S123A and wild-type $3 \beta$-HSD increase by $2 \cdot 7$-fold when the $\mathrm{pH}$ is raised from 7.4 to the optimal $\mathrm{pH} 9.7$, but $\mathrm{S} 124 \mathrm{~A}$ exhibits very low residual $3 \beta$-HSD activity that is $\mathrm{pH}$-independent.

These kinetic analyses strongly suggest that the Ser124 residue completes the catalytic triad for the $3 \beta$-HSD activity. Since there are 29 Ser residues in the primary structure of human $3 \beta-H S D 1$, our homology model of the catalytic domain has been validated by this accurate prediction. A role for Ser124 in the binding of the isomerase substrate, which is the $3 \beta$-HSD product-steroid of the bifunctional enzyme protein, is also suggested. These observations further characterize the structure/function relationships of human $3 \beta-H S D$ and bring us closer to the goal of selectively inhibiting the type 1 enzyme in placenta to control the timing of labor or in hormone-sensitive breast tumors to slow their growth.
\end{abstract}

Journal of Molecular Endocrinology (2004) 33, 253-261

\section{Introduction}

The human type 1 (placenta, skin, mammary gland, prostate and endometrium) and type 2 (gonads and adrenals) isoforms of $3 \beta$-hydroxysteroid dehydrogenase $(\mathrm{EC} \quad 1 \cdot 1 \cdot 1 \cdot 145) /$ steroid $\Delta^{5}-\Delta^{4}$-isomerase (EC $5 \cdot 3 \cdot 3 \cdot 1)(3 \beta$-HSD/isomerase) are encoded by two distinct genes which are expressed in a 
tissue-specific pattern (Rheaume et al. 1991). $3 \beta$-HSD/isomerase catalyzes the conversion of $3 \beta$ hydroxy-5-ene-steroids (dehydroepiandrosterone, pregnenolone) to 3-oxo-4-ene-steroids (androstenedione, progesterone) on a single, dimeric protein containing both enzyme activities (Thomas et al. 1989). Androstenedione is converted by placental aromatase and $17 \beta$-hydroxysteroid dehydrogenase 1 (17 $\beta$-HSD 1) to estradiol, which participates in the cascade of events that initiates labor in humans (Kacsoh 2000, Rainey et al. 2002). In addition to placenta and other human peripheral tissues, the type 1 enzyme is selectively expressed in breast tumors (Gingras et al. 1999), where it catalyzes the first step in the conversion of circulating dehydroepiandrosterone to estradiol to promote tumor growth. In human adrenals, type $23 \beta$-HSD/ isomerase is required for the production of cortisol and aldosterone (Rainey et al. 2002). Determination of the structure/function relationships of the type 1 enzyme may lead to the development of specific inhibitors of type $13 \beta$-HSD/isomerase that can help control the timing of labor and slow the growth of hormone-sensitive tumors without compromising steroidogenesis in the adrenal enzyme.

Mammalian 3 $\beta$-HSD/isomerase is a member of the short-chain dehydrogenase/reductase (SDR) family of enzymes. The Rossmann-fold coenzyme domain $(\beta-\alpha-\beta-\alpha-\beta-\alpha-\beta)$ and the $\mathrm{Y}-\mathrm{X}-\mathrm{X}-\mathrm{X}-\mathrm{K}$ catalytic motif in that domain are highly conserved in the SDR family (Jornvall et al. 1995). Many members of the SDR family utilize a catalytic triad of Ser, Tyr and Lys residues to perform the oxidoreductase enzyme reaction (e.g. 17ß-HSD1, UDP-galactose-4-epimerase) (Liu et al. 1997). A Tyr residue acts as the catalytic base, the hydroxyl group of Ser binds to the targeted oxo group to stabilize the substrate, and a Lys residue binds to the nicotinamide ribose and lowers the $\mathrm{pKa}$ of the phenolic hydroxyl group of the key Tyr to promote the proton transfer (Filling et al. 2002). In a few species of $3 \beta$-HSD (macque, bovine, rat I, II and IV, guinea pig and chicken), Thr124 is positioned to perform the function of Ser124 (Simard et al. 1996, Morel et al. 1997). Our homology model of the three-dimensional structure of human $3 \beta$ HSD1 has been used to predict key amino acid residues involved in catalysis and coenzyme specificity (Thomas et al. 2002, 2003). Our previous mutagenesis study supported roles for Tyr154 and Lys158 in the catalysis of human $3 \beta$-HSD 1
(Thomas et al. 2002). In the current study, our homology model has predicted a catalytic role for either Ser123 or Ser124. Hence, the S123A and S124A mutants of human $3 \beta$-HSDl have been produced to evaluate the function of these amino acids in the catalysis of the enzyme. Since there are 29 Ser residues in each monomer of the homodimeric enzyme (Thomas et al. 2002), this study also tests the accuracy of our homology model.

\section{Materials and methods}

\section{Materials}

Dehydroepiandrosterone and pyridine nucleotides were purchased from Sigma (St Louis, MO, USA); 5-androstene-3,17-dione from Steraloids, Inc. (Wilton, NH, USA); reagent grade salts, chemicals and analytical grade solvents from Fisher Scientific (Pittsburgh, PA, USA). Glass-distilled, deionized water was used for all aqueous solutions.

\section{Site-directed mutagenesis}

With the Advantage cDNA PGR kit (BD Biosciences Clontech, Palo Alto, CA, USA) and pGEM-3ßHSD1 as template (Thomas et al. 1998), double-stranded PCR-based mutagenesis was performed to create the cDNA encoding the S123A and S124A mutant enzymes. The forward and reverse primers used to produce $\mathrm{S} 123 \mathrm{~A}$ are listed (with the mutant codon in bold italics): 5'-TAC ACCGCTAGGATAGAGGTAGG-3' (forward); 5'-TATGGTAGGGGTGTAGATGAAGACT-3' (reverse). The primers used to produce S124A were as follows: 5'-CACGAGTGCGATAGAGG TAGCG-3' (forward); 5'-CGTCTATGGGACTG GTGTAGATG-3' (reverse). The presence of the mutated codon and integrity of the entire mutant $3 \beta$-HSD cDNA were verified by automated dideoxynucleotide DNA sequencing using the Big Dye Terminator Cycle Sequencing Ready Reaction kit (PE Applied Biosystems, Foster City, CA, USA). Chou-Fasman and GarnierOsguthorpe-Robson analysis of each mutant enzyme was used to choose amino acid substitutions that produced no apparent changes in the secondary structure of the protein (Protlyze program, Scientific and Educational Software, State Line, PA, USA). 


\section{Expression and purification of mutant and wild-type enzymes}

The mutant $3 \beta$-HSD cDNA was introduced into baculovirus as previously described (Thomas et al. 1998). Recombinant baculovirus was added to $1.5 \times 10^{9} \mathrm{Sf9}$ cells $(1 \mathrm{~L})$ at a multiplicity of infection of 10 for expression of each mutant enzyme. The expressed mutant and wild-type enzymes were separated by SDS-polyacrylamide (12\%) gel electrophoresis, probed with our anti-3 $\beta$-HSD polyclonal antibody and detected using the ECL Western blotting system with antirabbit, peroxidaselinked secondary antibody (Amersham Pharmacia Biotech, Piscataway, NJ, USA). Each expressed enzyme was purified from the $100000 \boldsymbol{g}$ pellet of the Sf9 cells (2 L) by our published method (Thomas et al. 1988, 1989, 2002). Each expressed, purified mutant and wild-type enzyme produced a single band $(42.0 \mathrm{kDa})$ on SDS-polyacrylamide $(12 \%)$ gel electrophoresis that comigrated with the human wild-type 1 control enzyme. Protein concentrations were determined by the Bradford method, using bovine serum albumin as the standard (Bradford 1976).

\section{Kinetics studies}

Michaelis-Menten kinetic constants for the $3 \beta$ HSD substrate were determined for the purified mutant and wild-type enzymes in incubations containing dehydroepiandrosterone (DHEA, $2-100 \mu \mathrm{M})$ and purified enzyme $(0.03 \mathrm{mg})$ at $27^{\circ} \mathrm{C}$ in $0.02 \mathrm{M}$ potassium phosphate, $\mathrm{pH} 7 \cdot 4$. The slope of the initial linear increase with time in absorbance at $340 \mathrm{~nm}$ per min (due to NADH production) was used to determine $3 \beta$-HSD activity. Kinetic constants for the isomerase substrate were determined at $27^{\circ} \mathrm{C}$ in incubations of 5-androstene-3,17-dione $(17-150 \mu \mathrm{M}), \mathrm{NADH}$ $(0.05 \mathrm{mM})$ and purified enzyme $(0.01 \mathrm{mg})$ in $0.02 \mathrm{M}$ potassium phosphate buffer, $\mathrm{pH} 7 \cdot 4$. Isomerase activity was measured by the initial absorbance increase at $241 \mathrm{~nm}$ (due to androstenedione formation) as a function of time. Changes in absorbance were measured with a Varian Cary 219 (Sugar Land, TX, USA) recording spectrophotometer. The Michaelis-Menten constants $\left(K_{\mathrm{m}}\right.$ and $\left.V_{\max }\right)$ were calculated from Lineweaver-Burke $(1 / \mathrm{S}$ vs $1 / \mathrm{V}$ ) plots and verified by Hanes-Woolf (S vs $\mathrm{S} / \mathrm{V}$ ) plots (17). The $\mathrm{k}_{\text {cat }}$ values $\left(\mathrm{min}^{-1}\right)$ were calculated from the $V_{\max }$ values $(\mathrm{nmol} / \mathrm{min}$ per $\mathrm{mg}$ ) and represent the maximal turnover rate (nmol product formed/min per nmol enzyme dimer).

Kinetic constants for the $3 \beta$-HSD cofactor were determined for the purified mutant and wild-type enzymes in incubations containing $\mathrm{NAD}^{+}(13-$ $100 \mu \mathrm{M})$, dehydroepiandrosterone $(100 \mu \mathrm{M})$ and purified enzyme $(0.03 \mathrm{mg})$ in $0.02 \mathrm{M}$ potassium phosphate, pH $7 \cdot 4$, at $27^{\circ} \mathrm{C}$, using the spectrophotometric assay at $340 \mathrm{~nm}$. Kinetic constants for the isomerase cofactor were determined in incubations of $\mathrm{NADH} \quad(2-50 \mu \mathrm{M}), \quad 5$-androstene-3,17-dione $(100 \mu \mathrm{M})$ and purified enzyme $(0.01 \mathrm{mg})$ in $0.02 \mathrm{M}$ potassium phosphate buffer, $\mathrm{pH} 7 \cdot 4$, at $27^{\circ} \mathrm{C}$, using the spectrophotometric assay at $241 \mathrm{~nm}$.

\section{pH-dependency studies}

The effects of $\mathrm{pH}$ on the residual $3 \beta$-HSD activities of the Y154F, K158Q, Y269S and K273Q mutants were measured in incubations at $27^{\circ} \mathrm{C}$ containing $5 \alpha$-androstan-3 $\beta$-ol-17-one $(100 \mu \mathrm{M}), \mathrm{NAD}^{+}$ $(0.2 \mathrm{mM})$ and purified enzyme $(0.08 \mathrm{mg})$ in 0.05 sodium phosphate pyrophosphate buffer, $\mathrm{pH} 7 \cdot 4$ or $9 \cdot 7$, using the $3 \beta$-HSD assay at $340 \mathrm{~nm}$.

\section{Modeling and sequence alignment}

The three-dimensional structure of human type 1 $3 \beta$-HSD/isomerase was modeled using the crystal structure (Thoden et al. 1996) of UDP-galactose 4-epimerase from Escherichia coli (Protein Data Bank Accession Code 1A9Z) as template, as described previously (Thomas et al. 2003).

\section{Results}

\section{Homology modeling targets the $3 \beta-H S D$ catalytic domain}

We recently reported that $40 \%$ of the fingerprint residues of $E$. coli UDP-galactose-4-epimerase, an SDR family member with a known crystallographic structure (Thoden et al. 1996), are conserved with respect to human 3 $\beta$-HSD1 (Thomas et al. 2003). The $3 \beta$-HSD and epimerase catalytic events are closely related in that both use a Tyr-X-X-X-Lys motif at the same position in the primary structure for the oxidation of a hydroxyl group (Gerratana et al. 2001). Similar to the catalytic Tyr149 and Lys 153 in UDP-galactose-4-epimerase, our sitedirected mutagenesis studies have identified Tyr 154 
and Lys 158 as the catalytic residues for human 3 $\beta$-HSD1 (Thomas et al. 2002). Another fingerprint residue of UDP-galactose-4-epimerase is the catalytic Ser124, and human 3 $\beta$-HSD contains a pair of Ser residues (Ser123 and Ser124) that correspond to this position in the homologous proteins. Thus, our model of the catalytic domain predicts that one of these serine residues, most likely Ser124, may complete the catalytic triad for human 3ß-HSD 1 (Fig. 1).

\section{Site-directed mutagenesis, expression and purification of the wild-type and mutant enzymes}

The3 $\beta$-HSD1 cDNA mutants (S123A and S124A) were produced by double-stranded, PCR-based mutagenesis and inserted into baculovirus, as described in Methods. As shown by the immunoblot in Fig. 2, the baculovirus system successfully expressed the mutant enzyme proteins as well as the human wild-type $3 \beta$-HSD1 in Sf9 cells. Each expressed enzyme was purified by our published method (Thomas et al. 1989) to apparent homogeneity, according to SDS-PAGE (Fig. 2).

\section{Kinetic comparisons of the purified wild-type and mutant enzymes}

The Michaelis-Menten kinetic values measured for substrate utilization by purified wild-type $3 \beta$-HSD 1 and by the S123A and S124A mutants are summarized in Table 1 . The S124A mutant enzyme has no detectable $3 \beta$-HSD activity. However, the S123A mutant exhibits a maximal turnover rate $\left(\mathrm{k}_{\text {cat }}\right)$ that is $24 \%$ of the wild-type $3 \beta$-HSD 1 activity and a $K_{\mathrm{m}}$ for DHEA that is threefold higher than 3 $\beta$-HSD1. S123A utilizes the isomerase substrate steroid with a similar $K_{\mathrm{m}}$ value compared with wild-type $3 \beta$-HSD 1, but the S124A mutant utilizes the isomerase substrate much less efficiently.

The cofactor kinetic values in Table 2 reveal that $\mathrm{S} 123 \mathrm{~A}$ reduces $\mathrm{NAD}^{+}$with a $K_{\mathrm{m}}$ value that is very similar to the $K_{\mathrm{m}}$ of $\mathrm{NAD}^{+}$for wild-type $3 \beta$-HSD 1 . Although S124A has no detectable 3 $\beta$-HSD activity in the cofactor kinetic study, the $K_{\mathrm{m}}$ values measured for NADH as an allosteric activator of isomerase are similar for S124A, S123A and wild-type $3 \beta$-HSD 1 .

\section{pH-dependency of the wild-type and mutant enzymes}

The $\mathrm{pH}$ dependency of the $3 \beta$-HSD activities of the S123A and S124A mutants can help determine whether one of these Ser residues is involved in catalysis. If the residual dehydrogenase activity of the mutant enzyme is pH-dependent, the substituted amino acid must not be catalytic because the residual activity has to be due to a different amino acid in the enzyme (Schlegel et al. 1998). Although $3 \beta$-HSD activity is undetectable for S124A using DHEA as substrate (Tables 1 and 2), the use of $5 \alpha$-androstan-3 $\beta$-ol-3-one as substrate enhances residual $3 \beta$-HSD by threefold to detectable levels. This $3 \beta$-hydroxy-5 $\alpha$-reduced steroid is not a substrate for isomerase activity; therefore, feedback inhibition by a 3-keto-4-ene product steroid (e.g. androstenedione) of $3 \beta$-HSD/isomerase does not limit the 3 $\beta$-HSD activity (Milewich et al. 1993). As shown in Table 3 , the wild-type $3 \beta$-HSD1 and S123A mutant exhibits substantial $3 \beta$-HSD activity at $\mathrm{pH} 7 \cdot 4$, and that activity is increased by $2 \cdot 7-$ to $2 \cdot 8$-fold at the optimal $\mathrm{pH} 9 \cdot 7$. However, even when $5 \alpha$-androstan-3 $\beta$-ol-3-one is used as substrate to enhance any residual activity, the $\mathrm{S} 124 \mathrm{~A}$ mutant enzyme has only trace $3 \beta$-HSD activity at $\mathrm{pH} 7 \cdot 4$, and this trace activity is not affected when the $\mathrm{pH}$ is increased to $9 \cdot 7$ (Table 3 ).

\section{Discussion}

Human $3 \beta$-HSD/isomerase is a unique member of the SDR family. The enzyme sequentially catalyzes the $3 \beta$-HSD activity followed by the isomerase activity on a single, dimeric protein. The coenzyme product of the $3 \beta-\mathrm{HSD}$ reaction, $\mathrm{NADH}$, induces a conformational change in the enzyme protein that activates the isomerase reaction (Thomas et al.

Figure 1 Ribbon structure of the active site of human $3 \beta$-HSD1 based on homology modeling. The primary sequences of $3 \beta-\mathrm{HSD} /$ isomerase and UDP-galactose-4epimerase were aligned as described in the text. The $\mathrm{NAD}^{+}$and DHEA structures are included. The catalytic Tyr154 and Lys158 residues (Thomas et al. 2002) as well as the potentially catalytic Ser123 and Ser124 residues are shown. Ser124 is shown hydrogen-binding

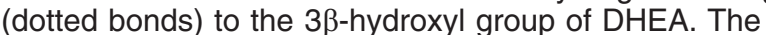
Asp36 residue is shown hydrogen-binding (dotted bonds) to the $2^{\prime}, 3^{\prime}$-hydroxyl groups of the adenosyl ribose group of NAD (Thomas et al. 2003). 


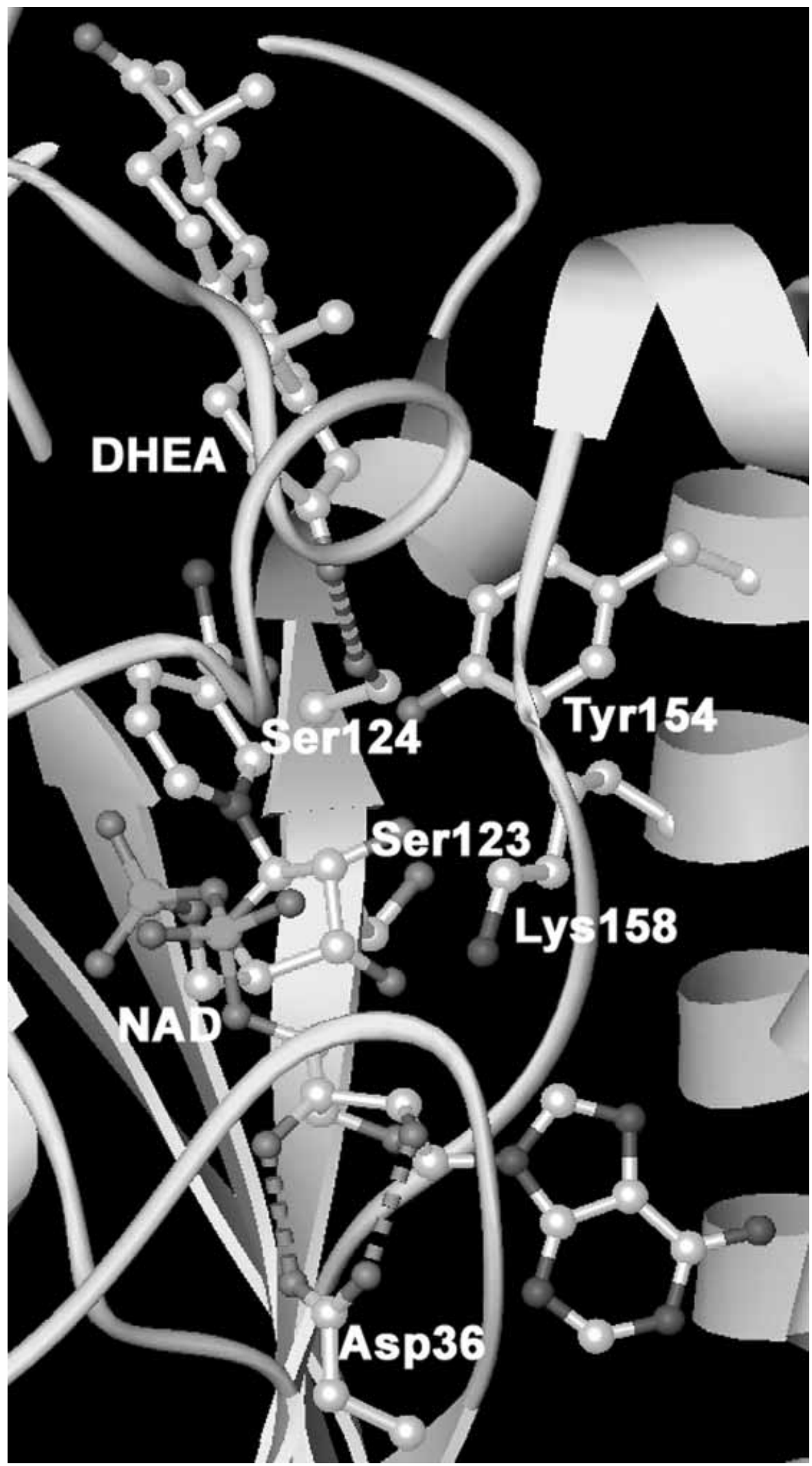




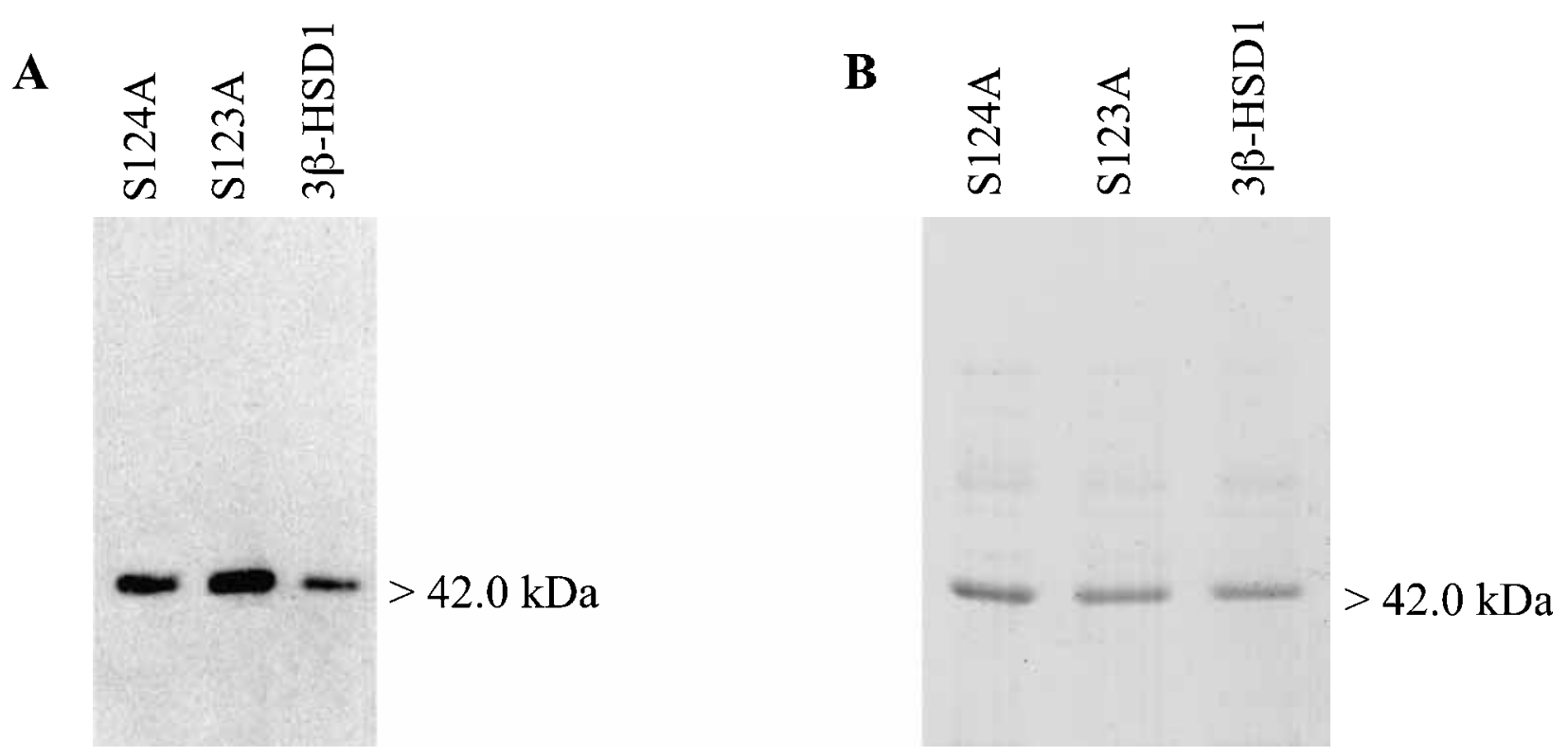

Figure 2 Western immunoblots showing the expression of the mutant and wild-type enzymes by baculovirus, and SDS-PAGE of the purified mutant and wild-type enzymes. (A) In the Western blot, the Sf9 cell homogenate $(3.0 \mu \mathrm{g})$ containing the S123A or S124A enzyme plus the purified control $3 \beta$-HSD1 $(0.05 \mu \mathrm{g})$ was separated by SDS-polyacrylamide (12\%) gel electrophoresis. The $42.0 \mathrm{kDa}$ band of the enzyme monomer was detected with our anti-3 $\beta$-HSD antibody. (B) In SDS-PAGE of the purified mutant enzymes, each lane was overloaded with $2 \cdot 0 \mu \mathrm{g}$ purified protein, and the bands were visualized by Coomassie blue staining.

1995). In our previous studies (Thomas et al. 1993, 1997), two tryptic peptides associated with the $3 \beta$-HSD and isomerase activities were localized in the primary structure of the type 1 enzyme with affinity-radiolabeled steroids. The Gly250 tryptic peptide contains Tyr253 and Asp257, which we have identified as the catalytic residues for the isomerase reaction (Mason et al. 1998, Thomas et al. 1998, 2003). When this peptide was protected from affinity alkylation by isomerase substrate or NADH (Thomas et al. 1994, 1997), the Glu135 tryptic peptide was identified. The Glu135 peptide contains Tyr154 and Lys158 in a YXXSK motif that is likely to be involved in $3 \beta$-HSD catalysis because of its location in the Rossmann-fold domain (Jornvall et al. 1995). Figure 3 localizes these catalytic residues in the primary structure of human $3 \beta$-HSDl and shows the positions of

Table 1 Substrate kinetics for the $3 \beta$-HSD and isomerase activities of the purified S123A, S124A and wild-type $3 \beta$-HSD1 enzymes

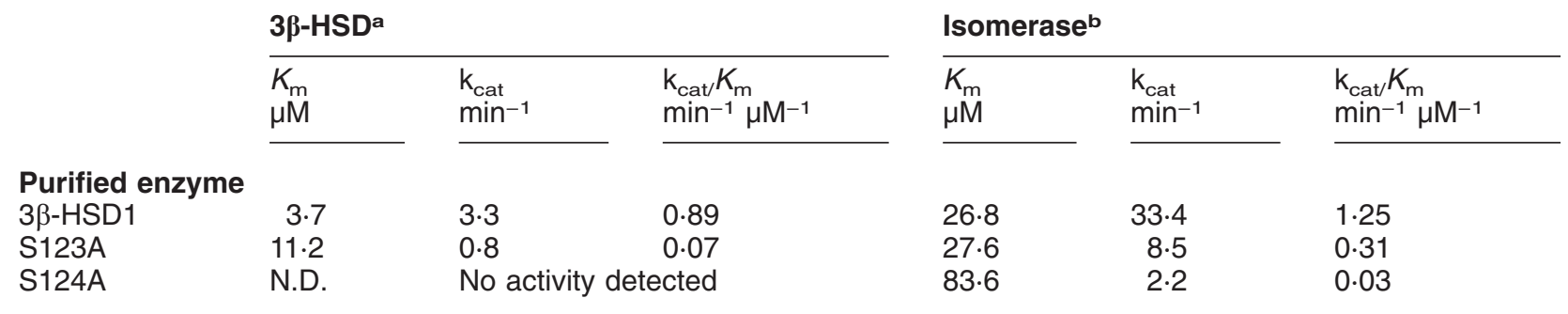

aKinetic constants for the $3 \beta-H S D$ substrate were determined in incubations containing dehydroepiandrosterone (2-100 $\mu M)$, NAD ${ }^{+}$ $(0.1 \mathrm{mM})$ and purified enzyme $(0.03 \mathrm{mg})$ in $0.02 \mathrm{M}$ postassium phosphate, $\mathrm{pH} 7.4,27^{\circ} \mathrm{C}$. $\mathrm{k}_{\text {cat }}$ values (nmol product formed/min per nmol enzyme dimer) were calculated from the $V_{\max }$ values. N.D., not determined.

bKinetic constants for the isomerase substrate were determined in incubations of 5-androstene-3,17-dione (15-100 $\mu \mathrm{M}) \mathrm{NADH}$ $(0.05 \mathrm{mM})$ and purified enzyme $(0.01 \mathrm{mg})$ in $0.02 \mathrm{M}$ postassium phosphate buffer, $\mathrm{pH} 7.4,27^{\circ} \mathrm{C}$. Each $K_{\mathrm{m}}$ and $\mathrm{k}_{\text {cat }}$ value represents the mean of triplicate measurements with a standard deviation $\leq 7 \%$ of single mutant enzyme preparations. 
Table 2 Coenzyme kinetics for the 3ß-HSD and isomerase activities of the purified S123A, S124A and wild-type $3 \beta$-HSD1 enzymes

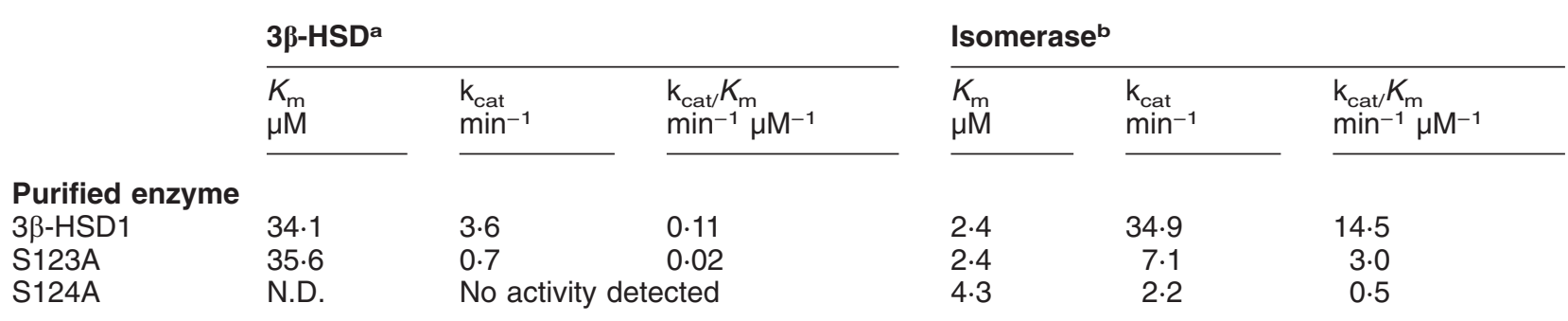

aKinetic constants for the 33-HSD cofactor were determined in incubations containing NAD+ $(20-100 \mu \mathrm{M})$, dehydroepiandrosterone $(100 \mu \mathrm{M})$ and purified enzyme $(0.03 \mathrm{mg})$ in $0.02 \mathrm{M}$ postassium phosphate, $\mathrm{pH} 7.4,27^{\circ} \mathrm{C}$. $\mathrm{k}_{\text {cat }}$ values (nmol product formed/min per nmol enzyme dimer) were calculated from the $V_{\max }$ values. N.D., not determined.

${ }^{b}$ Kinetic constants for the isomerase cofactor were determined in incubations of NADH $(2-50 \mu \mathrm{M}) 5$-androstene-3,17-dione $(100 \mu \mathrm{M})$ and purified enzyme $(0.01 \mathrm{mg})$ in $0.02 \mathrm{M}$ postassium phosphate buffer, $\mathrm{pH} 7.4,27^{\circ} \mathrm{C}$. Each $K_{\mathrm{m}}$ and $\mathrm{k}_{\text {cat }}$ value represents the mean of triplicate measurements with a standard deviation $\leq 6 \%$ of single mutant enzyme preparations.

S123 and S124 plus the other 27 Ser residues (underlined).

In agreement with a similar motif $\left({ }^{149} \mathrm{Y}-\mathrm{X}-\mathrm{X}-\mathrm{X}\right.$ $\mathrm{K}^{153}$ ) in UDP-galactose-4-epimerase (Liu et al. 1997), the Tyr154 and Lys 158 residues appear to be catalytic residues for $3 \beta$-HSD according to the kinetic profiles of the mutant Y154F and K158Q enzymes (Thomas et al. 2002). Our homology model of the active site of $3 \beta$-HSD (Fig. 1) localizes these residues in close proximity to the bound A-ring of DHEA and the nicotinamide moiety of $\mathrm{NAD}^{+}$. Identification of the third member of the catalytic triad, Ser, would have been difficult before the development of the homology model. There are 29 Ser residues in the $3 \beta$-HSD primary structure (Thomas et al. 2002), but the model predicts that only Ser 123 or Ser124 is oriented properly to hydrogen bond to the $3 \beta$-hydroxyl group of DHEA and stabilizes the substrate for catalysis by Tyr 154 and Lys 158.
With DHEA as substrate, the S124A mutant enzyme lacks measurable $3 \beta$-HSD activity, but the S123A mutant retains $24 \%$ of control $3 \beta-H S D$ activity. The extremely low residual $3 \beta$-HSD activity of the S124A mutant observed with $5 \alpha$-androstane- $3 \beta$-ol-17-one as substrate was not increased by raising the $\mathrm{pH}$ from $7 \cdot 4$ to the optimal $\mathrm{pH} 9 \cdot 7$. However, the $3 \beta$-HSD activity of the S123A mutant was increased $2 \cdot 8$-fold by this shift in $\mathrm{pH}$, and this $\mathrm{pH}$-dependent increase was mirrored by the wild-type $3 \beta$-HSD activity. The lack of $\mathrm{pH}$ dependency of the residual $3 \beta$-HSD activity of S124A strongly suggests that no other amino acid in the enzyme, even Ser123, can perform the catalytic function of Ser 124. According to these data, the Ser 124 residue appears to complete the catalytic triad for human $3 \beta$-HSD 1 .

The effects of the mutations on the isomerase activity are also instructive. The S124A mutant utilizes the isomerase substrate steroid with a 3-fold

Table 3 Dependency of the residual $3 \beta-H S D$ activities of the purified mutant enzymes on $\mathrm{pH}$

pH 7.4

\begin{tabular}{|c|c|c|}
\hline \multicolumn{3}{|c|}{ pп 7.4} \\
\hline & $\mathrm{nmol} / \mathrm{min}$ per $\mathrm{mg}^{1}$ & $\%$ WT1 \\
\hline \multicolumn{3}{|c|}{ Purified enzyme } \\
\hline $3 \beta-H S D 1$ & $41 \cdot 6 \pm 1 \cdot 2$ & 100 \\
\hline S123A & $9 \cdot 2 \pm 0.5$ & 22 \\
\hline S124A & $2 \cdot 2 \pm 0 \cdot 2$ & 5 \\
\hline
\end{tabular}

\section{pH 9.7}

\begin{tabular}{lrll}
\hline $\mathrm{nmol} / \mathrm{min}$ per $\mathrm{mg}$ & & $\% \mathrm{WT1}$ & \\
& & & activity ratio \\
$111 \pm 2 \cdot 1$ & 100 & $2 \cdot 7$ \\
$25 \cdot 8 \pm 0 \cdot 4$ & 23 & $2 \cdot 8$ \\
$2 \cdot 1 \pm 0.3$ & 2 & 1.0
\end{tabular}

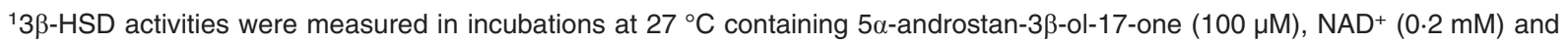
purified enzyme $(0.08 \mathrm{mg})$ in $0.05 \mathrm{M}$ sodium phosphate pyrophosphate buffer, $\mathrm{pH} 7.4$ or pH 9.7. WT1 is human wild-type $3 \beta-\mathrm{HSD} 1$. Values are the means \pm standard deviations of triplicate determinations of single mutant enzyme preparations. 
1

T G W

F $\underline{S}$ K L $Q$ N K T K L T V L E G D I L D E P F L K R A C Q D V 123124

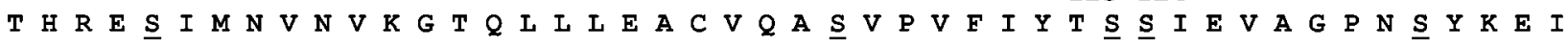
$154 \quad 158$

I $Q$ N $N$ G H

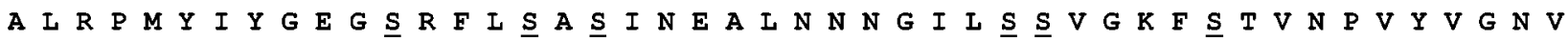
$253 \quad 257$

A W A H I I A L R A L $Q$ D P K K A P $\underline{S}$ I R G N F T Y Y I S D D T P H $Q$

$\underline{S}$ K E F G L R L D $\underline{S}$ R

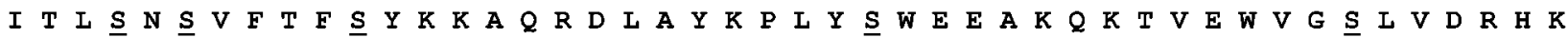
372

E T I K $\underline{S}$ K T $Q$

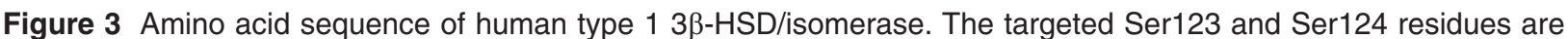
labeled, and all of the 29 Ser residues are underlined. The catalytic Tyr154 and Lys158 residues in the 3 $\beta$-HSD domain are labeled (Thomas et al. 2002). The critical Tyr253 and Asp257 residues in the isomerase catalytic domain are also noted (Thomas et al. 2003).

higher $K_{\mathrm{m}}$ and a 15 -fold lower maximal turnover rate $\left(\mathrm{k}_{\mathrm{cat}}\right)$ relative to the wild-type enzyme. This kinetic profile of S124A suggests that Ser124 participates in the alignment of 5-androstene-3,17dione for the isomerase reaction. These data support our model for sequential activities of the bifunctional enzyme: the $3 \beta$-HSD activity oxidizes DHEA to form 5-androstene-3,17-dione, which remains bound as the substrate steroid of the isomerase activity (Thomas et al. 1989, 1995). In contrast, the S123A mutant utilizes the isomerase substrate with the same $K_{\mathrm{m}}$ and with $25 \%$ of the maximal isomerase activity of the wild-type enzyme, which is the same decrease in $\mathrm{k}_{\text {cat }}$ measured for the $3 \beta$-HSD activity of S123A. The kinetic profile of S123A suggests that the removal of this hydroxyl R-group adjacent to the critical Ser 124 hinders the proper alignment of DHEA and 5 -androstene-3,17-dione in the enzyme active site to some extent, but Ser 123 clearly is not a catalytic residue for $3 \beta$-HSD or a key substrate-alignment residue for isomerase.

The coenzyme kinetic profiles suggest that the S123A and S124A mutations alter only substrate utilization by the enzyme. The $K_{\mathrm{m}}$ values of $\mathrm{S} 123 \mathrm{~A}$ measured for $\mathrm{NAD}^{+}$as the cofactor for $3 \beta$-HSD activity and for NADH as the allosteric activator of isomerase are almost identical to those of wild-type $3 \beta$-HSD 1. Although the complete lack of $3 \beta$-HSD activity by $\mathrm{S} 124 \mathrm{~A}$ prevented the determination of a $K_{\mathrm{m}}$ value for the utilization of $\mathrm{NAD}^{+}$, there was sufficient isomerase activity remaining to measure a $K_{\mathrm{m}}$ value for $\mathrm{NADH}$ that was very similar to that of wild-type isomerase. These kinetic data are consistent with Ser 124's serving as a critical residue for substrate, but not for coenzyme utilization.

The correct prediction that Ser124 functions with Tyr 154 and Lys 158 to complete the catalytic triad responsible for the human $3 \beta-\mathrm{HSD} 1$ activity validates our homology model of the tertiary structure of the enzyme active site. This validation complements our previous study in which the homology model accurately identified Asp36 as the residue responsible for the strict preference of $\mathrm{NAD}^{+}$as cofactor for the $3 \beta-\mathrm{HSD}$ activity and of NADH as the activator of isomerase instead of $\mathrm{NADP}^{+}$or NADPH respectively (Thomas et al. 2003). The homology model can be used to target other key amino acids responsible for subunit interactions of the enzyme dimer, coenzyme 
binding, membrane interactions and differences between human 3B-HSD1 and 3ß-HSD2 to characterize further the structure/function of this key steroidogenic enzyme.

\section{References}

Bradford MM 1976 A rapid and sensitive method for the quantitation of microgram quantities of protein utilizing the principle of protein-dye binding. Analytical Biochemistry 72 248-254.

Filling C, Berndt KD, Benach J, Knapp S, Prozorovski T, Nordling E, Ladenstein R, Jornvall H \& Oppermann U 2002 Critical residues for structure and catalysis in short-chain dehydrogenases/reductases. Fournal of Biological Chemistry 277 25677-25684.

Gerratana B, Cleland WW \& Frey PA 2001 Mechanistic roles of Thr134 Tyr160, and Lys164 in the reaction catalyzed by dTDP-glucose 4,6-dehydratase. Biochemistry 40 9187-9195.

Gingras S, Moriggi R, Groner B \& Simard J 1999 Induction of $3 \beta$-hydroxysteroid dehydrogenase $/ \Delta^{5}-\Delta^{4}$ isomerase type 1 gene transcription in human breast cancer cell lines and in normal mammary epithelial cells by interleukin- 4 and interleukin- 13 . Molecular Endocrinology 13 66-81.

Jornvall H, Persson B, Krook M, Atrian S, Gonzalez-Duarte R, Jeffery J \& Ghosh D 1995 Short-chain dehydrogenases/reductases (SDR). Biochemistry 34 6003-6013.

Kacsoh B 2000 Reproductive endocrinology. In Endocrine Physiology, pp 559-560. New York: McGraw-Hill.

Liu Y, Thoden JB, Kim J, Berger E, Gulick AM, Ruzicka FJ, Holden HM \& Frey PA 1997 Mechanistic roles of tyrosine 149 and serine 124 in UDP-galactose 4-epimerase from Escherichia coli. Biochemistry 36 10675-10684.

Mason JI, Naville D, Evans BW \& Thomas JL 1998 Functional activity of $3 \beta$-hydroxysteroid dehydrogenase/isomerase. Endocrine Research 24 549-557.

Milewich L, Shaw GE, Mason JI, Carr BR, Blomquist CH \& Thomas JL 1993 3ß-Hydroxysteroid dehydrogenase activity in the tissues of human fetus determined with $5 \alpha$-androstane- $3 \beta, 17 \beta$-diol and dehydroepiandrosterone as substrates. Fournal of Steroid Biochemistry and Molecular Biology 45 525-537.

Morel Y, Mebarki F, Rheaume E, Sanchez R, Forest MG \& Simard J 1997 Structure-function relationships of $3 \beta$-hydroxysteroid dehydrogenase: contribution made by the molecular genetics of 33-hydroxysteroid dehydrogenase deficiency. Steroids 62 176-184.

Rainey WE, Carr BR, Sasano H, Suzuki T \& Mason JI 2002. Dissecting human adrenal androgen production. Trends in Endocrinology and Metabolism 13 234-239.

Rheaume E, Lachance Y, Zhao H-F, Breton N, Dumont M, de Launoit Y, Trudel C, Luu-The V, Simard J \& Labrie F 1991 Structure and expression of a new complementary DNA encoding the almost exclusive 3 beta-hydroxysteroid dehydrogenase/delta 5-delta 4-isomerase in human adrenals and gonads. Molecular Endocrinology 5 1147-1157.

Schlegel BP, Jez J \& Penning TM 1998 Mutagenesis of 3 alpha-hydroxysteroid dehydrogenase reveals a 'push-pull' mechanism for proton transfer in aldo-keto reductases. Biochemistry 37 3538-3548.
Simard J, Durocher F, Mebarki F, Turgeon C, Sanchez R, Labrie Y, Couet J, Trudel C, Rheaume E, Morel Y et al. 1996 Molecular biology and genetics of the $3 \beta$-hydroxysteroid dehydrogenase/ $\Delta 5-\Delta 4$ isomerase gene family. Fournal of Endocrinology $\mathbf{1 5 0}$ S189-S207.

Thoden JB, Frey PA \& Holden HM 1996 Crystal structures of the oxidized and reduced forms of UDP-galactose 4-epimerase isolated from Escherichia coli. Biochemistry 35 2557-2566.

Thomas JL, Berko EA, Faustino A, Myers RP \& Strickler RC 1988 Human placental $3 \beta$-hydroxy-5-ene-steroid dehydrogenase and steroid 5-4-ene-isomerase: purification from microsomes, substrate kinetics and inhibition by product steroids. Fournal of Steroid Biochemistry 31 785-793.

Thomas JL, Myers RP \& Strickler RC 1989 Human placental $3 \beta$-hydroxy-5-ene-steroid dehydrogenase and steroid 5-4-ene-isomerase: purification from mitochondria and kinetic profiles, biophysical characterization of the purified mitochondrial and microsomal enzymes. Fournal of Steroid Biochemistry 33 209-217.

Thomas JL, Nash WE, Myers RP, Crankshaw MW \& Strickler RC 1993 Affinity radiolabeling identifies peptides and amino acids associated with substrate binding in human placental $3 \beta$-hydroxy- $\Delta^{5}$-steroid dehydrogenase. Fournal of Biological Chemistry 268: 18507-18512.

Thomas JL, Nash WE, Crankshaw MW \& Strickler RC 1994 Affinity labeling in the presence of the reduced diphosphopyridine nucleotide, $\mathrm{NADH}$, identifies peptides associated with the activities of human placental $3 \beta$-hydroxy- $\Delta^{5}$-steroid dehydrogenase/ isomerase. Fournal of the Society for Gynecologic Investigation 1 155-163.

Thomas JL, Frieden C, Nash WE \& Strickler RC 1995 An $\mathrm{NADH}$-induced conformational change that mediates the sequential $3 \beta$-hydroxysteroid dehydrogenase/isomerase activities is supported by affinity labeling and the time-dependent activation of isomerase. Foumal of Biological Chemistry 270 21003-21008.

Thomas JL, Evans BW \& Strickler RC 1997 Affinity radiolabeling identifies peptides associated with the isomerase site in human type I (placental) 3 $\beta$-hydroxysteroid dehydrogenase/isomerase. Biochemistry 36 9029-9034.

Thomas JL, Evans BW, Blanco G, Mercer RW, Mason JI, Adler S, Nash WE, Isenberg KE \& Strickler RC 1998 Site-directed mutagenesis identifies amino acid residues associated with the dehydrogenase and isomerase activities of human type I (placental) $3 \beta$-hydroxysteroid dehydrogenase/isomerase. Fournal of Steroid Biochemistry and Molecular Biology 66 327-334.

Thomas JL, Evans BW, Blanco G, Mason JI \& Strickler RC 1999 Creation of a fully active, cytosolic form of human type I $3 \beta$-hydroxysteroid dehydrogenase/isomerase by the deletion of a membrane-spanning domain. Fournal of Molecular Endocrinology 23 231-239.

Thomas JL, Mason JI, Brandt S, Spencer BR \& Norris W 2002 Structure/function relationships responsible for the kinetic differences between human type 1 and type $23 \beta$-hydroxysteroid dehydrogenase and for the catalysis of the type 1 activity. Fournal of Biological Chemistry 277 42795-42801.

Thomas JL, Duax WL, Addlagatta A, Brandt S, Fuller RR \& Norris W 2003 Structure/function relationships responsible for coenzyme specificity and the isomerase activity of human type 1 $3 \beta$-hydroxysteroid dehydrogenase/isomerase. Fournal of Biological Chemistry 37 35483-35490.

Received 20 January 2004 Accepted 12 May 2004 